\title{
Egypt's Premier Medical Student Research Group: A New Model for Medical Student Research in Developing Countries
}

\author{
Ahmed S. Negida ${ }^{1}$ \\ 1. Neurosurgery, Zagazig University, Zagazig, EGY \\ Corresponding author: Ahmed S. Negida, ahmed01251@medicine.zu.edu.eg
}

\begin{abstract}
The involvement of medical students in scientific research has been widely advocated over the last decades in order to fulfill the need for a new generation of physicians who can apply evidence-based medicine. Efforts to involve medical students in scientific research have been described by individual institutions. In developing countries, students are less involved in research owing to the limited time and resources. Hereby, we describe our three-year experience with a novel model for medical student research in Egypt.
\end{abstract}

Categories: Family/General Practice, Medical Education, Epidemiology/Public Health

Keywords: medical student research, medical education, evidence based medicine

\section{Editorial}

The involvement of medical students in scientific research has been widely advocated over the last decades. Educational institutions are preparing generations of scientist physicians who can advance medical sciences and bridge the gap with clinical practice. Additionally, the evolution of evidence-based medicine has changed the face of medical practice and medical education. Paul Glasziou stated that "a twenty-first century's clinician who cannot critically read a research paper is as unprepared as someone who cannot examine the cardiovascular system and measure the blood pressure" [1].

In developed countries, many educational institutions have involved student research into their educational program [2-4]. However, in developing countries, few reports have described the involvement of medical students in research. Common barriers towards student research in Egypt are lack of time, resources, and training [5]. Hereby, we report our experience in the Medical Research Group of Egypt (MRGE, www.negida.com/teams/mrge-egypt/). MRGE was established in 2014 as a non-governmental, non-profit, online-based, nationwide network of medical students across all Egyptian universities.

Received 02/03/2018

Review began 02/04/2018 Review ended 11/04/2018 Published 11/08/2018

(๑) Copyright 2018 Negida. This is an open access article distributed under the terms of the Creative Commons Attribution License CC-BY 3.0., which permits unrestricted use, distribution, and reproduction in any medium, provided the original author and source are credited.
MRGE provides medical students with a free online training of (1) database and literature search, (2) clinical study designs, (3) basics of biostatistics, (4) evidence synthesis, (5) critical appraisal, and (6) scientific writing and academic publishing. Additional training is provided through our regular interactive, hands-on workshops in different Egyptian universities.

Successful students who complete our training are matched into student interest groups working on an evidence synthesis project or a review of the literature. Research teams should include at least one senior student with experience in research methodology and a clinician or faculty member to provide the clinical expertise for the research team (Figure 1). 


\section{Cureus}

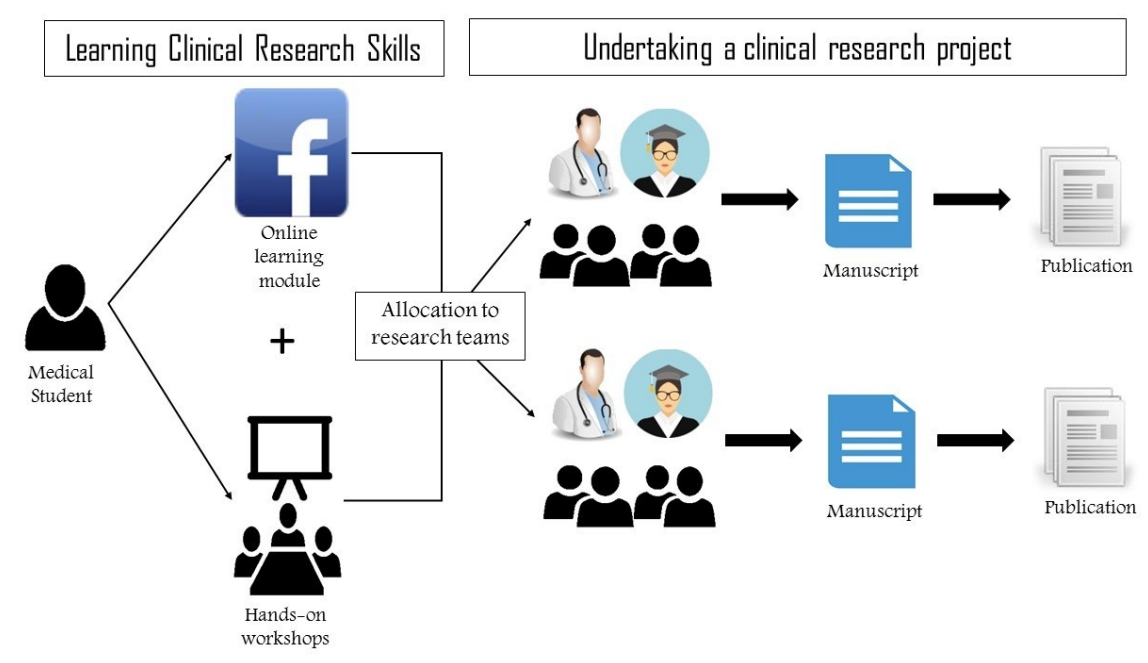

\section{FIGURE 1: Flow diagram}

A flow diagram of the two phases of the medical student research model of the Medical Research Group of Egypt

Since this model was initiated in 2014, 300 medical students from all the Egyptian universities have joined MRGE, 400 students were trained through our hands-on workshops, and other 1000 students joined our online learning module. This model has yielded several scientific publications, mostly systematic reviews, meta-analyses, and traditional review articles in many medical fields, including, but not limited to, neurology, oncology, hepatology, virology, and surgery. Interestingly, over time, hardworking students have the chance to take their collaboration up to participation in primary clinical research projects (for example, clinicaltrials.gov registration no: NCT02785510 and NCT02772744) and performing basic science experiments.

We recommend the replication of our non-governmental, online-based, student-led model in other developing countries.

\section{Additional Information}

\section{Disclosures}

Conflicts of interest: In compliance with the ICMJE uniform disclosure form, all authors declare the following: Payment/services info: All authors have declared that no financial support was received from any organization for the submitted work. Financial relationships: Ahmed Negida declare(s) a grant from International Parkinson's and Movement Disorder Society. Ahmed Negida declare(s) a grant from Asian Pacific Academy of Ophthalmology. Ahmed Negida declare(s) personal fees from Clinart MENA Contract Research Organization (Dubai, UAE). Ahmed Negida declare(s) personal fees from DATACLin CRO (Cairo, Egypt). Ahmed Negida declare(s) personal fees from Ghalioungui (Egypt). Paid lecture . Ahmed Negida declare(s) personal fees from System Analytic (UK). Honorarium. Other relationships: Ahmed Negida is the founder and chairman of Medical Research Group of Egypt (MRGE: http://www.negida.com/teams/mrgeegypt/).

\section{References}

1. Glasziou P, Burls A, Gilbert R: Evidence based medicine and the medical curriculum. BMJ, 2008:704-705. 10.1136/bmj.a1253

2. Hunskaar S, Breivik J, Siebke M, Tømmerås K, Figenschau K, Hansen J-B: Evaluation of the medical student research programme in Norwegian medical schools. A survey of students and supervisors. BMC Med Educ. 2009, 9:43. 10.1186/1472-6920-9-43

3. Jacobs CD, Cross PC: The value of medical student research: the experience at Stanford University School of Medicine. Med Educ. 1995, 29:342-346. 10.1111/j.1365-2923.1995.tb00023.x

4. Cursiefen C, Altunbas A: Contribution of medical student research to the Medline-indexed publications of a German medical faculty. Med Educ. 1998, 32:439-440.

5. Mostafa SR, Khashab SK, Fouaad AS, Abdel Baky MA, Waly AM: Engaging undergraduate medical students in health research: students' perceptions and attitudes, and evaluation of a training workshop on research methodology. J Egypt Public Health Assoc. 2006, 81:99-118. 